\title{
Interacionismo Simbólico e Transplante Hepático
}

Resumo: Muitas são as possibilidades teórico-metodológicas oferecidas pela sociologia Ciências Sociais da para a abordagem da medicina contemporânea e seu alto grau de complexidade. A esUniversidade Federal do Paraná. colha do interacionismo simbólico para a análise do transplante hepático deve-se ao fato de se abordar, neste artigo, questões que têm importância central para autores como E-mail: zecarasia@ Goffman e Strauss. As observações realizadas com e Equipe de Transplante Hepático com gmail.com os indivíduos doentes hepáticos crônicos à espera para transplante e os transplantados constituem o objeto da discussão. Abordam-se aqui questões relacionadas à linguagem, ao status e à identidade dos doentes e transplantados. A pesquisa foi realizada no Serviço de Transplante Hepático (STH-HC) do Hospital de Clínicas da UFPR.

Palavras-chave: Interacionismo Simbólico, Status, Identidade

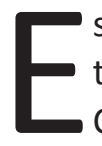

ste artigo é resultado de um pesquisa realizada no Serviço de Transplante Hepático do Hospital de Clínicas da Universidade Federal do Paraná. A Coleta de dados ocorreu no período compreendido entre abril de 2010 e março de 2012, usando-se o recurso da observação participante, no ambulatório clínico do Transplante Hepático do hospital. Na pesquisa, buscou-se compreender as questões que envolvem doentes hepáticos graves crônicos e transplantados, tanto em relação ao tratamento, quanto ao transplante e à posição social que ocupam na relação com a equipe médica (a partir daqui, Equipe), com o círculo familiar e de amigos. Os indivíduos aqui considerados possuem origens e condições sociais diferenciadas. Entre os 20 indivíduos observados, 12 homens e 8 mulheres, a média de idade é de 48 anos. 0 mais velho estava com 72 anos na época da coleta dos dados e o mais jovem com 28 . No que diz respeito à profissão, entre as mulheres tem-se 1 empregada doméstica, 2 professoras de ensino médio, 4 donas de casa e 1 funcionária pública. Entre os homens, 1 engenheiro, 1 administrador de empresas, 1 advogado, 2 militares, 1 vigilante, 1 funcionário público federal, 2 motoristas de caminhão, 1 empresário do ramo de distribuição de alimentos e 2 pequenos comerciantes.

Das mulheres, 5 são casadas, 1 solteira e duas divorciadas. Dentre os homens, 1 solteiro e os demais casados. A renda familiar oscila entre 1 e 15 salários mínimos, com uma renda média de 6 salários mínimos. Entre as mulheres, a renda familiar é mais baixa, pois quatro delas não possuem renda, só contam com a renda do marido. A renda familiar, nesse caso, varia entre 1 e 5 salários mínimos, sendo a renda familiar média de 3 salários mínimos. 
2. Utiliza-se Equipe, aqui, no sentido apresentado por Goffman (1974). A Equipe é composta por médicos cirurgiões, médicos clínicos, residentes, psicólogos, alunos de medicina em estágio e funcionários do ambulatório que estão em contato direto com doentes e transplantados nos diferentes níveis de atendimento do Serviço de Transplante Hepático do Hospital.

\section{A llusão Linguística}

O primeiro dado que chama a atenção observando os transplantados e candidatos a transplante refere-se ao grau de conhecimento que possuem da doença, do tratamento e do transplante. Isso coloca, logo de início, a interrogação: como esses indivíduos, diferentemente de outros portadores de doenças crônicas graves, sabem tanto sobre sua condição? Como dominam o vocabulário que a princípio supõe o conhecimento médico, ao qual não se tem acesso tão facilmente?

As questões do conhecimento sobre a doença e o domínio da linguagem médica que revelam sempre que se referem à sua condição constituem o primeiro estranhamento. De onde vinha tanta intimidade com o conhecimento e com o vocabulário médico? Esse estranhamento permaneceu por um longo tempo e foi se desfazendo, na medida em que se pode observar a forma como a Equipe ${ }^{2}$ que os atende lhes fornecia explicações sobre o diagnóstico, o curso da doença, o tratamento e o transplante. $O$ detalhamento dessas informações chama atenção para outra questão: por que quem os atende no ambulatório manifesta-se tão preocupado com explicações detalhadas sobre o que se passa? O que está por trás dessa explicação é que os cuidados que o transplantado toma são fundamentais para o sucesso do transplante. Na medida em que o trabalho de campo se desenvolveu, foi possível perceber que essas informações circulavam no ambulatório entre os transplantados e candidatos ao transplante, constituindo uma rede de comunicação na qual a Equipe está inserida e onde a terminologia médica passa a ser compartilhada por todos. Aqui convém citar um novo estranhamento: em que medida o uso desse vocabulário indica, de fato, apropriação de conhecimento e produz efeitos de significação que ajudam o indivíduo a lidar com sua história e com sua condição de doente?

O que aos poucos foi se tornando claro é que a constante insistência da Equipe em comunicar claramente aos doentes o que se passa com eles produz, como efeito, uma ampliação e sofisticação do vocabulário sobre a doença e o transplante. Ou seja, o que resulta dessa situação é uma aquisição lexical com a qual não conseguem produzir uma narrativa que explique sua condição e que expresse a apropriação de conhecimento. Por vezes, me deixei levar pela ideia de uma apropriação do conhecimento, ou seja, fui envolvido pelo jogo linguístico, como se o indivíduo, ao falar de si e de sua condição usando o vocabulário médico, estivesse fazendo uma construção que, de fato, expressasse um novo conhecimento de si e uma nova percepção de sua condição. O domínio do vocabulário médico não os retira de nenhuma situação concreta de dificuldade quando alguma coisa não vai bem com a saúde. O novo vocabulário não articula experiência de sofrimento e esquema interpretativo. O que se manifesta na fala não corresponde a uma atitude ou uma ação de enfrentamento da dificuldade que se apresenta. Os efeitos imaginários e mesmo reais da doença e do transplante 
permanecem intocados.

Nesse sentido, pode-se pensar em separação entre as palavras, o self, a ação e a condição do indivíduo. A ação diante da dificuldade momentânea é conduzida pela emoção ou pelos afetos, dentre os quais prevalece o medo de que algo grave possa estar acontecendo. Observando a forma como interpretam sua condição em momentos de crise, foi possível compreender que o vocabulário utilizado não corresponde aos esquemas interpretativos utilizados pela Equipe. Ao falarem, usam um sistema de nomeação e classificação sem o domínio da "perspectiva do classificador" (STRAUSS, 1999, p. 39). Considerando-se que o vocabulário médico está referenciado a um sistema classificatório, percebe-se que os indivíduos doentes, embora o empreguem, não conseguem operar com esse novo vocabulário, pois a palavra enquanto expressão de classificação de um objeto ou situação "não apenas dirige uma ação aberta, mas também desperta um conjunto de expectativas com relação ao objeto assim classificado" (ibidem, p. 41).

A ausência da perspectiva do classificador entre esses indivíduos torna o vocabulário destituído de seu efeito classificatório e, portanto, de qualquer propriedade significativa para a ação. Como afirma Strauss:

Quando classificamos, nossas expectativas se defrontam necessariamente com o passado e com o futuro. Expectativas têm a ver com relações de consequência entre nós mesmos e o objeto. Todavia, as expectativas repousam também sobre lembranças de experiências passadas com objetos semelhantes - no nosso entender - ao que está na nossa frente.

Já que isto acontece dessa maneira, as classificações não só trazem consigo nossas antecipações, mas também aqueles valores que tínhamos experimentado quando encontramos as coisas, as pessoas, ou os eventos ora classificados. (idem)

O que se observa é que o vocabulário "compartilhado" produz a impressão de que as dificuldades que perpassam as interações entre doentes e Equipe foram superadas. Mas, na falta do conhecimento do modelo classificatório utilizado pela Equipe, os doentes permanecem com uma margem de ação restrita e em uma posição subalterna na interação. Nesse sentido, os processos interacionais são marcados pela assimetria entre os indivíduos, na qual predomina a Equipe. São o conhecimento e as expectativas desta que se impõem. A posição de subalternidade do doente permite pensar a forma como se confrontam dois esquemas culturais distintos, o do doente e o da Equipe. Ao mesmo tempo, aponta para a compreensão de como a ação de uns prevalece sobre a ação dos outros, ou seja, como a ação da Equipe é dominante na situação. Assim, o conceito de 
3. Sobre a alienação no sentido empregado aqui, ver Goffman (2011).
4. Para Goffman (2011), a pseudoconversação ocorre nas interações não faladas, "interações que são parecidas com conversações em que os símbolos trocados não são discursos, e sim gestos estilizados como a troca de cumprimentos não verbais" (GOFFMAN, 2011, p. 127-8) situação nos ajuda a entender o que os indivíduos consideram nessa relação e nas ações dela decorrentes. Muitas vezes, a Equipe se deixa levar pela falsa compreensão de que, na medida em que o indivíduo se refere à sua condição usando o vocabulário médico, os problemas de comunicação na interação estão resolvidos e esta se realiza num plano de equilíbrio e igualdade, portanto livre da alienação ${ }^{3}$. E mais, que o indivíduo está convivendo melhor com as dificuldades clínicas. Boltansky (1989) afirma que o doente faz uma seleção dos termos médicos, retendo aqueles que de uma maneira ou outra reconhece, mesmo ignorando seu significado científico. Mas devemos nos perguntar se o reconhecimento de termos médicos é suficiente para resolver a questão que se enfrenta aqui.

O que acaba de ser afirmado se sustenta pela observação dos indivíduos candidatos a transplante e aos transplantados, que revelam muitas inquietações sobre sua condição. $\mathrm{O}$ uso dos termos médicos, embora sempre apropriado, não condiz com a condição observada do indivíduo. Nesse sentido, o vocabulário não é capaz de ajudá-lo na organização da experiência de doença e também não traduz um novo esquema cultural adquirido a partir da interação com a Equipe. Pode-se afirmar, então, que a fala não corresponde à forma como os indivíduos vivenciam a experiência de ser um indivíduo que espera por um transplante ou que leva consigo um órgão de outro. Há uma decalagem entre o vocabulário utilizado e a condição vivida.

Quando a experiência é compartilhada com outros indivíduos doentes no ambulatório, a comunicação se dá através da linguagem cotidiana. Diante desse dado, se pode considerar que a interação com a Equipe tem como foco a doença e, na interação com os demais doentes no ambulatório, o foco é a vida de cada um, na qual a doença é apenas parte da história e da carreira pessoal.

Nesse sentido, pode-se pensar em uma pseudo-conversação do indivíduo com a Equipe $^{4}$. O uso que se faz aqui dessa categoria não corresponde à dimensão não verbal da qual trata Goffman (2011) ao se referir às interações pautadas por gestos estilizados. Trata-se, aqui, de uma conversação sustentada em palavras vazias; conversação que não indica a reorganização da carreira pessoal frente à doença, pois, pelo que se vê, o emprego do vocabulário médico pelo doente não implica em mudança de atitude diante de uma possível crise.

É comum sentir-se fascinado pelo indivíduo que, embora leigo, domina o vocabulário médico sobre a doença e o transplante. Entretanto, um pouco de atenção e de cuidado foram necessários para que essa ilusão se desfizesse e se compreendesse o que estava em jogo no uso do vocabulário e do discurso que articulam com precisão saber médico e experiência de doença. Na verdade, o que se percebeu depois de um tempo de observação foi que o indivíduo doente 
buscava palavras que o aproximassem cada vez mais da Equipe. Uma hipótese possível é de que o que estava em jogo para os indivíduos doentes na interação com a Equipe são pelo menos duas dimensões: a do papel social de doente que deve apresentar-se com prontidão para atender as demandas da equipe e a outra, de uma interação focada no propósito de construir laços os mais estreitos possíveis com a Equipe. O doente busca, portanto, estabelecer uma fachada que o aproxime cada vez mais da Equipe e, mais, que represente a expectativa desta.

A vivência do papel de doente que os indivíduos identificam para si está ancorada no jogo teatral entre o eu e o outro e incorpora as expectativas do outro. A assimilação do vocabulário é a forma que marca essa incorporação para os envolvidos na interação. O jogo entre equipe e indivíduo doente torna visível a luta pelo controle da interação quando esta é focada na doença. Como afirma Strauss, "parte do processo de obtenção de controle sobre a interação é decerto inconsciente, embora talvez não no mesmo sentido enfatizado pelos psiquiatras" (STRAUSS, 1999, p. 95).

Assim, não se pode afirmar que esse uso da linguagem médica seja adotado deliberadamente - expresso na hipótese acima -, tendo em vista ações futuras desses indivíduos mas, ao contrário, como afirma Strauss, "certas coisas a respeito da postura, da entonação, da fala de um homem, do ritmo e dos modos da interação forçam inconscientemente outros a reagir da maneira apropriada a seu status alegado - pelo menos aparentemente" (idem).

E, aqui, nos deparamos novamente com a assimetria na interação e com o reconhecimento do outro e sua posição na cena. Se isso é correto, o indivíduo doente, mesmo que de forma inconsciente, se esforça - ao reconhecer o status da Equipe -, no sentido de elevar seu status perante a mesma, assumindo a linguagem desta quando se refere à doença.

Assim, o indivíduo doente, ao afirmar que sofre de uma "cirrose criogênica", não está falando necessariamente de um tipo de cirrose referenciada a uma classificação das doenças crônicas do fígado - a qual ele desconhece - e com um curso específico. Ele fala de uma doença que afeta o fígado, que o impede de funcionar normalmente e por razões que ele desconhece se chama cirrose criogênica.

Na continuação das observações, tanto a cirrose alcoólica, quanto a criogênica e a medicamentosa adquirem, para o doente, um mesmo e único sentido: doença incurável ou doença crônica, embora tenham diferentes nomes. Em um plano mais geral, se observa que toda a classificação das doenças crônicas do fígado fica reduzida ao dito "doença que precisa de transplante". Embora os indivíduos façam uso das diferentes denominações - que correspondem aos tipos distintos de doença - o uso do vocabulário médico decorre do convívio prolongado 
com a Equipe. O que não se pode desconhecer, porém, é que o uso da nomenclatura médica das doenças do fígado pelos doentes atribui-lhes certo status diante da Equipe e também dos familiares, embora nomear corretamente, nesse caso, não signifique necessariamente compreender. Não se observa por parte do doente atitudes em relação à doença que correspondam a um novo esquema de conhecimento sobre a experiência. O que se observa, porém, é que o domínio do vocabulário médico pelo doente o aproxima da Equipe e sustenta a pseudo-percepção de que controla a interação.

\section{Status e Derrocada do Eu}

Em Espelhos e Máscaras, Strauss afirma que o controle das interações está relacionado aos ciclos de humor e à autoconcepção. "Um pesar ou uma depressão profunda também leva outros a uma excitação interacional" (STRAUSS, 1999, p. 96). Talvez, se possa pensar que os indivíduos doentes estejam experimentando um estado e excitação interacional em relação à equipe. Excitação esta marcada pelas exigências da produção da identidade de doente grave, papel que Ihe confere o diagnóstico médico. Da excitação interacional decorre, assim, um status temporário, correspondente à nomeação de sua doença. Dessa forma, a aderência ao vocabulário médico pode ser considerada um passo na direção da nova identidade. Não se trata, portanto, somente de reconhecer o status alegado à equipe, mas também de um reconhecimento pelo indivíduo do status temporário que a Equipe Ihe confere na presença da doença crônica grave. Mais tarde, esse status temporário evolui para o status de transplantado (LAZZARETTI, 2002, 2008; STASCECHEN, 2009). Assim, ao falar do indivíduo doente, fala-se de um indivíduo em situação de liminaridade (VAN GENNEP, 1960), quer do ponto de vista do status, quer do ponto de vista do curso da doença. Desta forma, status temporário e liminaridade são categorias presentes no processo de produção da identidade desses indivíduos. Pois a identidade de que se fala nesse momento, para os indivíduos à espera do transplante, é, como o status, uma identidade temporária, porque o curso da doença é irreversível e as opções que se apresentam para o doente são o transplante ou a morte.

Não se pode esquecer, também, nessa discussão, que a demanda do outro é um dado constituinte dos processos de interação e, como tal, da construção da identidade. Como afirma Strauss (1999, p. 98), "uma exigência apresentada deve ser aceita ou recusada; isto é, devemos projetar a imagem sugerida ou alguma outra, e comportar-nos, e esperar que os outros se comportem, de acordo com ela". Nesse sentido, ao status temporário atribuído ao indivíduo doente corresponde uma imagem assumida, que também é temporária e que será redefinida com a realização do transplante. Há uma concordância entre status 
e imagem - ambos temporários - no período pré-transplante. Essa concordância possibilita que o indivíduo doente manifeste comportamentos e atitudes que correspondam não só à sua condição mas, antes de tudo, às expectativas da Equipe. Após a realização do transplante, a correspondência entre imagem e status é refeita, a situação de liminaridade e o status temporário são abolidos e surge, em seu lugar, o transplantado - um novo status e com variações importantes em seu papel, como mostra Lazzaretti (2002). Imagem e status de transplantado, se, por um lado, referem-se ao indivíduo que recebeu um órgão, por outro, são designações que correspondem à expectativa da Equipe em relação ao outro (ao indivíduo doente). Nesse quadro os processos de interação entre Equipe e transplantado se modificam. Trata-se agora, para o indivíduo, de agir e de se comportar segundo o novo status conquistado, que não será mais temporário. Afirmar que o status, aqui, é conquistado e não atribuído se refere ao fato de que o indivíduo que o alcança atuou em acordo com a Equipe, no sentido de poder chegar à realização do transplante. Explico: submeteu-se aos cuidados, ao tratamento e a todas às demais exigências médicas para a realização do transplante.

Esse status, uma vez conquistado, o marcará para sempre. Diante da Equipe, será sempre um transplantado e, como tal, necessitará do acompanhamento desta por toda a vida. A dependência dos cuidados da Equipe está na constituição desse status e é um componente de seu papel social. Os vínculos de dependência do doente em relação à Equipe são concebidos como vínculos de reciprocidade. Para os doentes, a Equipe salvou-lhes a vida: "devo o que sou hoje aos médicos do HC. Só estou aqui porque eles me trataram e continuam tratando (...). Devo fazer sempre o que eles dizem (...)" (mulher, 45 anos, divorciada) 5 . Para a Equipe: "ela é uma paciente muito especial, não perde uma consulta e segue corretamente as prescrições (...). Comporta-se como uma transplantada (...) Cuida-se muito bem!" (médica, 48, anos, solteira).

Se reciprocidade e dependência estão no centro das interações entre a Equipe e o transplantado, por outro lado, fundam novo papel social para este último e redefinem, em certa medida, novas atribuições ao papel da Equipe. Do transplantado exige-se agora cuidados que implicam em mudança radical dos hábitos alimentares, controle do peso, atividade física regular, trabalho sem muito esforço físico e, principalmente, regularidade no uso de medicamentos; da Equipe, se exige dedicação e atenção constante ao transplantado durante toda a vida. Assim, o transplante estabelece vínculos duradouros e atitudes que correspondentes ao status de cada um.

Isso posto, pode-se pensar que, ao se fundarem vínculos duradouros e laços de reciprocidade entre Equipe e transplantado, os processos de interação estão regularizados, normatizados. Não é bem assim! A cada nova consulta, as 5. Em consideração
à privacidade dos
informantes cujos
depoimentos são
citados ao longo do
texto, evito identi-
ficá-los, apontando
somente o sexo, a
idade e a condição. 
expectativas de uns e de outros se reatualizam. Os elementos trazidos pelo transplantado são sempre um desafio para a Equipe. Nunca a situação se repete, sempre existem dados novos da experiência vivida pelo transplantado que precisam ser considerados: uma dor de cabeça constante, um indicador bioquímico fora do padrão, uma queixa de inapetência alimentar, por exemplo, precisam ser considerados. Apesar dos protocolos de tratamento e cuidado, cada caso é considerado em sua singularidade. Para a Equipe, manter sob controle as queixas e possíveis intercorrências com o transplantado significa dar uma resposta satisfatória para sua própria expectativa. Ao resolver clinicamente a situação do transplantado, a Equipe responde às expectativas deste e reafirma sua posição diante dele.

Tomar o transplantado em sua singularidade, ouvi-lo com atenção, realizar um bom exame físico, explicar a prescrição e as condutas para além de seu conteúdo ético é a estratégia disponível para a Equipe manter o controle das interações. Controle este que se atualiza na medida em que as expectativas do transplantado são satisfeitas. Voltemos a lembrar com Strauss (1999) que o controle das interações não passa necessariamente por mecanismos e atitudes conscientes e que, portanto, essa estratégia está incorporada no ethos médico e não é usada deliberadamente com tal fim.

As mudanças no status e nos papéis sociais pelas quais passa o indivíduo transplantado implicam necessariamente na construção de nova identidade. Lazzaretti (2002) mostra isso em seu trabalho sobre transplantados renais. Após o transplante, os indivíduos se referem e se autoclassificam em duas categorias: a) "indivíduo transplantado" e b) "indivíduo com transplante". Essa classificação remete a duas posições subjetivas manifestadas pelos indivíduos. O transplantado é aquele que vive com muitas limitações e que continua identificado com a doença ou, no dizer de Canguilhem (1995), alguém que não conseguiu estabelecer um padrão de normalidade para si. Para os indivíduos com transplante, Lazzaretti (2002) identificou uma posição subjetiva na qual as limitações impostas pelo transplante não os impedem de levar uma vida normal, ou seja, são indivíduos que estabeleceram para si um novo padrão de normalidade.

No caso do transplante hepático, não se faz aqui a discussão sobre as diferenças entre um indivíduo e outro em relação às posições subjetivas que assumem. Continua-se falando de transplantados, independentemente dessa diferença estabelecida por Lazzaretti (2002), não porque ela não exista, mas porque não é o foco desta discussão. Toma-se neste texto, a identidade a partir das proposições de Goffman $(1988,2008)$ e Strauss (1999).

Observar indivíduos doentes no ambulatório permitiu perceber, além dos eventos relacionados com a interação como a linguagem, o status e os papéis, 
foi possível também perceber a transformação das carreiras pessoais (STRAUSS, 1999) e de identidade do doente à espera do transplante e especialmente do transplantado. $O$ primeiro elemento a apontar para a transformação da carreira pessoal e da identidade é a derrocada do eu, que se inicia com o estabelecimento do diagnóstico.

Quando o indivíduo recebe o diagnóstico de uma doença crônica e grave do fígado, inicia um novo momento em sua vida, que será marcado pelas idas constantes ao hospital, uma rotina de medicamentos e de cuidados que modificam seu ritmo de vida. As exigências do tratamento e a espera na fila para o transplante implicam em muitos casos no "abandono" de papéis - tanto no âmbito do trabalho, quanto no âmbito familiar e no círculo das relações sociais. Abrir mão de determinados papéis se desdobra em perda de um status conquistado ao longo da vida a favor do novo status de indivíduo doente grave que precisa de um transplante. A derrocada do eu se aprofunda a cada nova etapa da doença e do tratamento. As complicações e internações constantes pelo agravamento da doença são indicadores claros desse processo. Cada vez mais o indivíduo se distancia de seu status anterior ao diagnóstico e dos papéis desempenhados até então.

Pode-se afirmar, aqui, que a derrocada do eu e o conjunto de questões que se colocam para o indivíduo apontam para o que Goffman (2008) considera a deterioração da identidade. Signos da doença como fraqueza, dificuldade de concentração, emagrecimento, aumento abdominal, perturbação mental, transmitem para o outro um conjunto de informações sobre a derrocada e a deterioração da identidade, que o torna desacreditável. "Antes do transplante eu cheguei a perder metade do meu peso normal. Só tinha barriga. Era pura água (...). As pessoas me estranhavam quando me viam. Eu fiquei horrível, não parecia mais eu" (homem, 42 anos, transplantado).

O que se observa nesse processo é que a derrocada do eu implica em um rebaixamento que se expressa não só pela perda do status conquistado e seus papéis em favor do status de doente grave, mas também pela perda de controle sobre as interações nos círculos mais próximos e a transformação da imagem. Pode-se admitir, embora não se tenha dados para isso, que esse rebaixamento implica na emergência de formas de estigmatização do indivíduo. Efeitos como isolamento e perda de potência do indivíduo permitem que se pense na existência de estigmas, que tem origem nas condições físicas deterioradas deste. "Eu fiquei tão fraco, mas tão fraco que não conseguia mais caminhar, passava o dia na cama. Não tinha vontade pra nada!" (homem, 62 anos, transplantado).

Pode-se depreender da fala acima que o indivíduo se autoestigmatiza, mas, em nenhum momento da pesquisa, observamos o indivíduo se queixando de 
ter sido estigmatizado. O mais próximo do estigma foram situações em que o indivíduo fala do estranhamento que sua imagem, deteriorada pelos efeitos da doença, causava no outro. "Eu estava tão feia que ninguém mais me reconhecia, nem eu mesmo! Não queria que ninguém me visse (...)" (mulher, 45 anos, transplantada).

A deterioração da imagem, a perda de status e papéis, ao incidir sobre o controle das interações atuam sobre o eu no sentido de fazer com que o indivíduo se recuse a interagir. Assim, se por um lado não se conseguiu dados mais consistentes que permitam falar de estigma por outro, pode-se falar de autoestigmatização.

A derrocada do eu é acompanhada pela derrocada moral do indivíduo, que agora se sente rebaixado pela perda de posição nos cenários em que costumava interagir. Esse prejuízo moral incide sobre a carreira pessoal do indivíduo (STRAUSS, 1999).

Nesse ponto, considerar os efeitos da derrocada moral sobre a biografia é uma via que permite pensar como a mudança de status e de papéis afetam o indivíduo. Um dos pontos a que se chegou foi que o indivíduo nessa condição "renuncia" à biografia construída; ou, se não se tratar de renúncia, pelo menos deve-se admitir que a doença grave e seus efeitos suspendem a biografia. Entende-se por suspensão da biografia, a ruptura de um padrão de regularidade das ações, atitudes, comportamentos e principalmente, de autopercepção. À sua condição de impotência física, corresponde a impotência moral, ou seja, perda de potência no âmbito da ação. É disso que se trata, em parte, quando se fala de transformação da carreira pessoal. E, aqui, é preciso observar que a potência de agir está diretamente relacionada às condições de investimento afetivo do indivíduo no objeto da ação. A situação de doente grave o envolve de tal forma que a doença passa ser o objeto predominante no cenário da ação. Nesse sentido, Freud (1981) nos ajuda a entender essa situação, quando afirma que, nas perdas, predomina sobre o sujeito a sombra do objeto perdido e um apagamento do outro, do mundo e, acrescente-se, da disposição para a interação.

O que se perde, ao deparar-se com um diagnóstico de doença grave, para além da saúde? Perde-se status, papel e reconhecimento. São essas perdas que agora incidem como sombras sobre o indivíduo, que se vê reduzido em sua condição: “Eu não era mais nada, era só um doente. Só pensava na doença e como me livrar dela pra voltar a ser o que eu era. Não foi fácil! Só tinha uma saída (...) só o transplante" (mulher, 42 anos, transplantada).

Tomando a doença como causa de derrocada do eu e seus efeitos sobre a carreira pessoal do indivíduo, podemos considerar com Strauss (1999) que 
esta representa um momento decisivo na vida do indivíduo. Um momento decisivo é um momento crítico em que se observa frequentemente "desalinhamento - surpresa, choque, pesar, ansiedade, tensão, frustração, autoquestionameto - , bem como a necessidade de experimentar o novo self, de explorar e validar as novas concepções, muitas vezes excitantes ou pavorosas" (SRAUSS, 1999, p. 102-103).

Suspender uma biografia construída na temporalidade do indivíduo é uma forma radical de desalinhamento. Embora a radicalidade do desalinhamento não se coloque logo no estabelecimento do diagnóstico, ela é experimentada em toda sua extensão por aqueles que já realizaram o transplante: "Eu estou muito bem, agradeço muito aos médicos deste hospital. Minha vida está muito boa, mas não sou mais o que eu era. A gente não volta a ser o mesmo, sempre tem um probleminha. Não consigo fazer tudo que eu fazia. É bem diferente!" (muIher, 28 anos, transplantada).

Os efeitos do desalinhamento se fazem sentir nas limitações impostas pelo transplante. Essas limitações exigem do indivíduo investimentos no sentido de projetar um novo eu e - por que não? - uma nova carreira pessoal. Este é o sentido do drama vivido na doença como experiência biográfica e existencial. Pois, como dizem os transplantados, não se volta ao que se era antes da doença, antes do transplante: "Agora não sou mais o mesmo! Nunca mais vou ser o mesmo" (homem, 56 anos, transplantado).

E, aqui, chegamos no núcleo das exigências que se colocam ao indivíduo transplantado: a projeção de uma nova identidade.

\section{A Projeção da Identidade entre Transplantados}

A carreira pessoal dos indivíduos observados mostrou como a doença crônica hepática muda sua condição, produz rupturas e altera de forma radical suas biografias. Trata-se, agora, de examinar como esses indivíduos projetam nova identidade.

Como se observou, Lazzaretti (2002) identificou duas posições subjetivas ou autopercepções desses indivíduos, os transplantados e os que vivem com transplante. Adota-se para esse ponto, como marco da discussão, a noção de transplantado, reunindo sob ela todos os indivíduos que receberam um transplante, independentemente de sua posição subjetiva.

É bom estabelecer, desde já, que a presença da doença hepática crônica representa para o indivíduo uma situação limite e que o tempo em que convive 
6. Quando nos referimos a curto espaço de tempo, estamos tomando como referência outras doenças crônicas como o diabetes, a hipertensão, etc. Assim, curto aqui dá mais uma ideia da doença e seu caráter de terminalidade do que uma dimensão temporal. com ela à espera do transplante sua situação é de liminaridade (GENNEP, 1960). A duração da convivência com a doença tem um tempo determinado para cada indivíduo, de acordo com o ritmo de sua evolução. Assim, o tempo de espera para o transplante varia para cada caso e a indicação do momento em que o transplante deve ser realizado depende de um conjunto de indicadores clínicos, que não vem ao caso discutir aqui.

Retomando o que foi dito e também Strauss (1999), o transplante é para o indivíduo um "momento decisivo," em sua carreira pessoal. Inclusive em sua carreira de doente, já que o transplante, ao mesmo tempo em que é a única medida terapêutica que pode devolver-Ihe certa qualidade de vida, é também uma decisão de alto risco, apesar dos avanços da tecnologia médica nesse campo. O transplante é mais que a exposição ao risco, é a chance de viver, pois a doença hepática grave, diferentemente de outras doenças crônicas, é sempre terminal ${ }^{6}$, levando o doente, em maior ou menor tempo, à morte.

Afirmar que o indivíduo se confronta com um momento decisivo em sua carreira é dizer que o que se impõe a ele neste momento é uma "mudança de identidade" (idem, p. 103). Em certa medida, procurou-se deixar isso claro quando se discutiu a derrocada do eu e a radicalidade dos efeitos da doença crônica grave para o indivíduo. Se, naquele momento, situou-se a discussão sobre a identidade de doente, agora, se trata de situar a questão no pós-transplante. Ou seja, pensar esse indivíduo agora como transplantado.

O desalinhamento de que fala Strauss não se resolve em curto espaço de tempo após o transplante. As incertezas e as exigências de um pós-operatório longo e delicado mantêm o indivíduo tenso, ansioso e atento aos possíveis sinais de complicação ou intercorrência. A introspecção que se observa nos primeiros meses do pós-operatório nos fala dos investimentos subjetivos do doente na tentativa de preservar seu eu: "ou faz o transplante ou morre" - como dizem os indivíduos - repercute durante longo tempo, diminuindo em seu horizonte as possibilidades de interação. As interações ficam, nessa fase, reduzidas aos encontros com a Equipe e com familiares mais próximos. Suas ações se orientam na perspectiva de preservação da vida e, nesse sentido, é fundamental a total adesão às prescrições feitas pela Equipe. $O$ indivíduo assume para si a condição de bom transplantado.

O "bom transplantado" é o indivíduo que se destaca entre os transplantados. Em geral, se apresenta bem humorado, de aspecto saudável, nunca está acima do peso, cuida da medicação, mantém uma rotina de trabalho, convive bem com a família e os amigos, valoriza o transplante como forma de renascimento e como ato heroico. Está sempre pronto para servir de exemplo aos candidatos a transplante, colaborando com a Equipe, relatando sua experiência bem 
sucedida àqueles que estejam enfrentando problemas com a medicação e com o estabelecimento de uma rotina de vida, bem como para os que continuam na espera pelo transplante. Assim, o "bom transplantado" demonstra, com seu exemplo, e sua imagem que a vida é possível e pode ser boa, mesmo depois de ter passado por uma experiência considerada limite. Essa imagem de si corresponde, em certa medida, às expectativas projetadas pela equipe. Ou seja, o indivíduo transplantado assume as prescrições e corresponde às expectativas da Equipe.

Já para os doentes em espera pelo transplante, a imagem que a Equipe projeta para ele é a de "bom paciente", que corresponde em expectativa ao que se espera do "bom transplantado". A Equipe interpreta a condição de "bom paciente" como um dado que projeta o sucesso do transplante, quando este for realizado. A nova identidade começa a ser moldada, portanto, a partir da condição que antecede ao transplante. Na lógica da Equipe, um "bom paciente" resulta num "bom transplantado".

Um transplantado, ao assumir a condição de modelo para os outros, ou pelo menos ao ser tomado como tal, assume um novo status para a Equipe, mas não só para ela, para a família, para os amigos e, principalmente, para aqueles que encontra no ambulatório e que passaram ou estão em vias de passar por um transplante.

É importante observar que, apesar da surpresa, das angústias - do desalinhamento - que a condição lhe reserva, o transplantado não só passa a ser o centro das muitas interações entre os doentes e a Equipe, mas divide com esta o controle dos processos interacionais quando se trata da relação entre a Equipe e os indivíduos que esperam o transplante. $O$ transplante lhe confere um poder que advém do heroísmo de ter sobrevivido à doença e ao procedimento cirúrgico: "A espera pelo fígado, o tratamento e a cirurgia foram difíceis (...) Eu tinha medo que não ia dar conta. Hoje me considero um herói. Estou renascido (...) sou outro" (homem, 38 anos, casado).

O heroísmo e o renascimento representados e alcançados pelo transplante reposicionam o indivíduo e seus papéis no cenário da clínica. Reposicionam também o transplantado nas relações familiares e no círculo de amigos. Valorizar a passagem pela doença e o transplante é parte das atribuições de seu papel, em todos os cenários dos quais participa. Porém, em muitos momentos, essa autopercepção heroica é rebaixada: "Estou muito bem, mas não sou mais o mesmo, nem sei por quanto tempo me manterei assim" (homem, 38 anos, casado).

A reciprocidade dos elogios entre Equipe - que valoriza as boas condições clínicas do transplantado, os cuidados que tem consigo - e transplantado - sobre 
a competência e a dedicação daquela - marcam as relações entre ambos. Nesse sentido, os processos interacionais entre o transplantado, a Equipe e os indivíduos que esperam por um transplante reforçam a construção de uma identidade fundada na coragem, na bravura. Bravura e coragem remetem à dramaticidade da experiência e é aí que o transplantado se constitui enquanto tal.

A dimensão dramática da experiência não se refere somente ao sofrimento físico, mas também aos conflitos enfrentados pelo indivíduo e pela Equipe no processo que vai da constatação da necessidade de um transplante até o momento da realização deste. Para a Equipe, manter o doente em condições clínicas que Ihe permitam, na hora adequada, ser transplantado e a disponibilidade do órgão para transplante são um desafio, pois colocam a questão de que resposta dará indicação à chamada para o transplante.

Para a Equipe, embora cada transplante seja único, existe um cálculo do risco que envolve o sucesso, não só do ato cirúrgico, mas do processo todo. Mesmo as intercorrências, quando acontecem, estão na ordem do previsível e dos fatores possíveis de serem controlados. Esse cálculo baseia-se no grau de desenvolvimento da medicina contemporânea e nos conhecimentos acumulados sobre transplante e orientam sempre a ação. A certeza clínica de quem deve receber o órgão naquele momento, porém, não é suficiente para garantir as expectativas da Equipe, pois existe um grau de imprevisibilidade no processo que escapa das formas conhecidas de controle. Do ponto de vista do candidato, os conflitos levam muitas vezes o indivíduo a recusar momentaneamente o transplante, em nome de não estar preparado.

Eu fui chamado três vezes para o transplante, nas duas primeiras eu desisti, "amarelei", como se diz. Na primeira eu estava em casa, tocou o telefone e era do hospital, dizendo que se eu quisesse tinham arrumado um fígado para mim. Fiquei assustado. Respondi que ia tomar um banho e que logo estaria no hospital. Saí do banho e disse para minha mulher: "não vou fazer o transplante." Liguei para o hospital e disse: "passem este fígado pra outro, eu não vou!" Passou uns três meses de novo, tocou o telefone era do hospital. Temos um fígado pra você venha logo! Respondi sem enrolar: "hoje não! Podem dar pra outro!" Na terceira vez, uns dois meses depois, me chamaram de novo. Aí me senti com coragem e vim. Mas não é fácil você tomar a decisão, porque tomada a decisão você sabe que é a vida ou a morte. Mas como eu estava muito ruim, nesse momento tanto fazia! (Homem, 42 anos, casado) 
A Equipe lida com esse tipo de situação dando mais tempo para a decisão do indivíduo. Nas situações de desistência temporária, o indivíduo aponta sempre que não está suficientemente preparado para o transplante e que fizera o que julgava ser correto naquele momento. Embora não fique explícito do que está falando quando responde que não está preparado, pode-se admitir a hipótese de que está falando de condições subjetivas? O que é certo é que o indivíduo defronta-se com seu eu rebaixado, impotente para agir. Mesmo sabendo que suas condições gerais melhoram e que ganha qualidade de vida, admite ser difícil adaptar-se à nova condição. Além da cirurgia delicada pela qual passará, fica muito assustado com o fato de saber que terá que tomar medicamentos, fazer acompanhamento médico para o resto de sua vida e, principalmente, o "não voltarei mais a ser quem era" (mulher, 28 anos, solteira). Ou seja, a iminência do transplante coloca de imediato a questão da identidade.

A percepção do risco pelo candidato, representado pela possibilidade de morrer, é um fato que pontua sempre a decisão de fazer o transplante quando chamado. Mas parece importante ler na recusa, desde o rebaixamento do eu, a impotência de agir e também, de que vida pode se instaurar após o transplante? A observação mostra que, nos casos bem sucedidos, e que são a maioria, os indivíduos debatem-se com a identidade de transplantados (LAZZARETTI, 2002). Ou, como diz a maioria deles: "estou bem, mas não sou mais o mesmo!". Outros ainda vão mais longe, escondendo do público a condição de transplantado:

Não comento com pessoas que não são da família que sou transplantado, que fiz um transplante de fígado. Isto não interessa pra ninguém, só interessa pra mim e para minha família. Não gosto de ficar falando por aí dessa experiência. Entendo que ela é algo que deve ser preservada no âmbito privado. Nem com os colegas de trabalho fico comentado. Claro que eles sabem, mas não abro muito o jogo. Isto não serve pra nada pra eles, pois não estão precisando de transplante. (Homem, 38 anos, casado)

Chama atenção ainda o fato de que, no ambulatório, enquanto espera a consulta, esse indivíduo não participa das conversas com outros transplantados ou com os que estão na fila de espera. Não se pronuncia quando o assunto é transplante. Não conversa com ninguém sobre sua experiência. É amável com todos, mas sempre fala de outros assuntos que não dizem respeito à experiência vivida. Conversa sobre futebol, política, notícias do dia, conta histórias do trabalho, mas não entra em nenhum tipo de assunto que envolva doença hepática, transplante ou medicação. Perguntado se está à espera ou se fez transplante, limitou-se a responder que fez transplante e acrescentou: "prefiro não falar disso". 
Um transplantado não é necessariamente um doente. Goffman (1988) ajuda a entender essa situação lembrando que existe um controle social que estipula as normas e facilmente pode considerar a diferença como um estigma, invés de acolhê-la. Assim, um transplantado que percebe sua diferença em relação ao outro percebe também que pode ser desacreditável. Os indivíduos transplantados que tentam ocultar sua situação pertencem à categoria dos que lutam para preservarem-se do estigma.

A construção e manutenção da identidade implica em ritos relacionados a ciclos interiorizados de repetição de atitudes, comportamentos, ações e expectativas. Não existe possibilidade de estabelecimento de uma autopercepção e de uma identidade sem ritualização. Muitas das ações dos indivíduos só são compreendidas levando-se em conta a contribuição da ritualização em seu desenvolvimento. E pode-se arriscar mais, uma identidade só pode ser assentada mediante a ritualização de comportamentos, ações e expectativas.

O "bom transplantado" tanto para a Equipe, quanto para o círculo familiar e dos amigos, é o indivíduo que cumpre à risca as prescrições médicas. Raramente apresenta complicações, seus exames de rotina sempre estão dentro de padrões clínicos aceitáveis, mantém-se no peso ideal, não falta às consultas. Muitas vezes a conversa entre dois indivíduos era interrompida porque um deles precisava tomar a medicação. O horário da medicação é respeitado em qualquer condição, como se fosse um processo ritual, ou pelo menos se assenta em atitudes ritualizadas. A hora do medicamento interrompe mesmo a conversa mais animada com a Equipe ou com outros transplantados.

Perguntados sobre a importância de tomar a medicação sempre no mesmo horário, a resposta que se obteve foi sempre a mesma: como são duas tomadas diárias precisam respeitar o intervalo entre elas: "Isto é sagrado! Não pode num dia tomar num horário e no outro dia noutro, isso atrapalha o tratamento" (homem, 47 anos, casado).

Chama atenção, ainda, que essa ritualização se expressa nos pequenos detaIhes. O horário é considerado até mesmo nos minutos:

(...) tomo remédio às 10 da manhã e às 10 da noite, isso é sagrado, não deixo passar um minuto do horário para não me prejudicar. Tem que cumprir com o horário, quem não cumpre arruma complicação. Eu uso o despertador do celular para me alertar que chegou a hora do remédio, esteja onde eu estiver. (Homem, 38 anos, divorciado)

O que está em questão não é se o indivíduo deve ou não cumprir o horário da medicação à risca, mas seu significado. Um transplantado só consegue 
manter-se nessa condição - e disso depende a conservação de sua identidade e seu status - sob cuidados e acompanhamento da Equipe que realizou o transplante e da família. Ou seja, o transplante não é cura, é tratamento e portanto, o indivíduo transplantando necessita manter os laços com a Equipe por toda a vida e não pode prescindir dos cuidados da família. Nesse sentido não só a rotinização, mas também a ritualização da medicação e dos cuidados é um meio de não frustrar as expectativas do outro e, ao mesmo tempo, de conservar a identidade de transplantado.

\section{Considerações Finais}

A identidade de transplantado, como qualquer outra, se estabelece na relação com o outro. $\mathrm{O}$ outro dessa relação é constituído pela Equipe de transplante e pelos familiares e amigos. O outro, através de suas expectativas, desde cedo, atua na direção dessa construção. A ação da Equipe para manter o indivíduo em tratamento e em condições clínicas de realizar o transplante é a estratégia que o projeta como transplantado. Para a família, a estratégia consiste em assumir com o doente e para o doente os cuidados complementares como a alimentação, a rotina de exercícios e o ritmo de sono, buscando, dentro do possível, manter o bem estar do mesmo.

Chegar à condição de transplantado compreende as várias etapas apresentadas neste artigo, que se constituem num conjunto de obstáculos a serem ultrapassados. O primeiro deles, como se observou, é a aderência às prescrições da Equipe. Aderência esta que, no caso analisado, mostra-se através da linguagem, mais precisamente, do uso do vocabulário médico na comunicação com o a Equipe. $E$, como tal, a aderência é uma necessidade transformada em virtude. O segundo refere-se a um conjunto de perdas que o indivíduo enfrenta a partir do diagnóstico de doença hepática crônica grave e da necessidade do transplante. Se a perda de status e a situação de liminaridade predominam nesse período, a observação aponta para a derrocada do eu como o evento mais significativo. Se derrocada do eu é o evento mais significativo para o doente, não deixa de ser importante também para a Equipe e para o círculo familiar e de amigos. Manter o ânimo do doente para que consiga realizar o transplante é o desafio enfrentado por todos os envolvidos com o doente, seja a equipe, seja a família, seja o círculo de amizades.

Enfrentar a cirurgia e o pós-operatório, longo e delicado, é o terceiro momento deste processo, no qual de fato se instaura o desafio de uma nova identidade, este é um momento decisivo na vida do doente, marcado pelo conflito, pois o indivíduo precisar escolher. A escolha é dramática, já que o conflito está em escolher a vida ou a morte. Nessa escolha se apresenta de forma irreversível o desafio de construir uma nova identidade. 
Abstract: Contemporary sociology offers many theoretical and methodological possibilities for this field of analysis. The choice of symbolic interactionism to analyze liver transplantation is due to the fact that this essay addresses issues of central importance to authors such as Goffman and Strauss. The observations of chronic liver disease patients in the queue for liver transplantation, and those who had already received donor organs, made alongside the Liver Transplantation Team, are the subject of this discussion. This essay inquires upon questions regarding the language, the status and the identity of both convalescent individuals and those who had already undergone transplant. The survey took place at the Liver Transplantation Service (STH-HC) at UFPR's Hospital de Clínicas. Keywords: Symbolic Interactionism, Status, Identity.

\section{Referências}

BOLTANSKI, Luc. As Classes Sociais e o Corpo. Rio de Janeiro: Graal, 1984, 185p. CANGULHEM, George. O Normal e o Patológico. Rio de Janeiro: Forense universitária, 1998

CICOUREL, Aaron, V. Le Raisonnement Médical. Paris: Seuil, 2002

GENNEP, Arnold Von. The Rites of Passage. Chicago: Chicago U.P, 1960, 198p.

GOFFMAN, Erving. A Representação do Eu na Vida Cotidiana. Petrópolis: Vozes, 1975, 233p

GOFFMAN, Erving. Estigma: Notas sobre a Manipulação da Identidade Deteriorada. 4. ed. Rio de Janeiro: Zahar, 1982.

GOFFMAN, Erving. Ritual de Interacão. Petrópolis: Vozes, 2011, 255p.

FREUD, Sigmund. “Duelo y Melancolia” In: Obras Completas. Madrid: Biblioteca, Nueva, 1989 [1915], t. II.

LAZZARETTI, Claire T. O Doador Vivo no Transplante Hepático: a dádiva na contemporaneidade. Curitiba, 2008. 240 f. Tese (Doutorado em Sociologia) - Setor de Ciências Humanas, Letras e Artes, Universidade Federal do Paraná.

. Transplante Renal: trajetória e reconstrução de identidade social.

Curitiba, 2002. 222 f. Dissertação (Mestrado em Sociologia) - Setor de Ciências Humanas, Letras e Artes, Universidade Federal do Paraná.

PARSONS, Talcott. The Social System. Glencoe: The Free Press, 1951, 575 p.

STASCECHEN, Luis F. Famílias Doadoras de Órgãos. Curitiba, 2009 167f. Dissertação (Mestrado em Sociologia) - Setor de Ciências Humanas Letras e Artes, Universidade Federal do Paraná.

STRAUSS, Anselm. L. Espelhos e Máscaras. São Paulo: Edusp, 1999, 177p.

STRAUSS, Anselm. L. \& GLASER, G. B. Chronic IIIness and Quality of Life. N.York: The C.V.Mosby, 1975, 160p. 